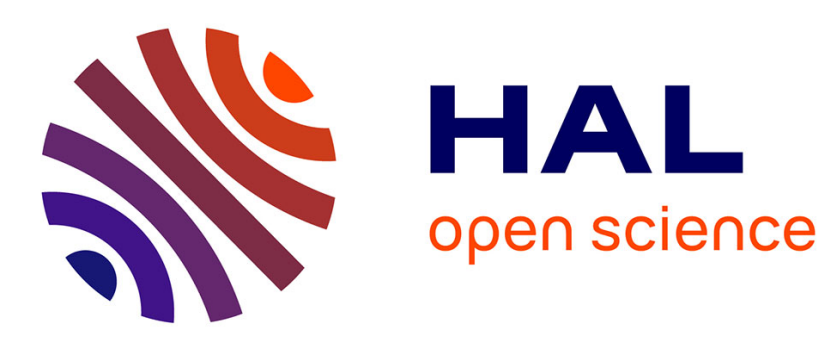

\title{
Organophosphorus and Iron Catalysis: Good Partners for Hydrometalation of Olefins and Alkynes
}

Duo Wei, Christophe Darcel

\section{To cite this version:}

Duo Wei, Christophe Darcel. Organophosphorus and Iron Catalysis: Good Partners for Hydrometalation of Olefins and Alkynes. Journal of Organic Chemistry, 2020, 85 (22), pp.14298-14306. 10.1021/acs.joc.0c01637 . hal-03024043

\section{HAL Id: hal-03024043 \\ https://hal.science/hal-03024043}

Submitted on 27 Nov 2020

HAL is a multi-disciplinary open access archive for the deposit and dissemination of scientific research documents, whether they are published or not. The documents may come from teaching and research institutions in France or abroad, or from public or private research centers.
L'archive ouverte pluridisciplinaire HAL, est destinée au dépôt et à la diffusion de documents scientifiques de niveau recherche, publiés ou non, émanant des établissements d'enseignement et de recherche français ou étrangers, des laboratoires publics ou privés. 


\section{Organophosphorus and Iron Catalysis: Good Partners for Hydrometalation of Olefins and Alkynes}

Duo Wei, Christophe Darcel*

Univ Rennes, CNRS, ISCR - UMR 6226, F-35000 Rennes, France, e-mail: christophe.darcel@univ-rennes1.fr

ABSTRACT: The last decades have seen an impressive development of iron complexes involving organophosphorus ligands applied in homogeneous catalyzed hydrometalation of olefins and alkynes. Two main topics will be covered in this review: (i) an overview of the achievements in the area of iron-catalyzed hydrophosphination, and then (ii) hydrosilylation, hydroborylation and hydromagnesiation reactions promoted by catalysts based on organophosphorus ligands and iron.

The fine development of low toxic, sustainable and highly efficient transition metal catalysts is one of the hottest research topics in modern synthetic chemistry. Nevertheless, this field was mainly dominated by precious metals for decades. Their substitution by more benign first row ones is thoroughly desired and nowadays is undoubtedly one of the meaningful challenges. As the most abundant transition metal in the Earth's crust, the application of iron in homogeneous catalysis is a highly valuable target for various organic transformations, ${ }^{1}$ including the chemoselective reduction and hydrofunctionalization of unsaturated compounds. $^{2-13}$ 
More particularly, in the area of functionalization of alkenes and alkynes, hydrometalation reactions represent an attractive pathway enabling to produce functionalized alkyl and alkenyl derivatives (e.g. with silicon, boron, magnesium or phosphorus) which have a wide range of applications in organic transformations. To promote them in a chemo-, regio- and stereoselective manner, the use of metal catalysts is usually required for the addition of metal-hydride bond to unsaturated C-C bonds. ${ }^{14-17}$ Recently, iron catalysts, and more particularly organophosphorus based ones, have emerged in this field exhibiting high activity and selectivity. This review provides an overview of the recent developments in the area of iron-catalyzed hydrometalation of olefins and alkynes. More particularly, it will report iron-catalyzed hydrophosphination, hydrosilylation, hydroborylation and hydromagnesiation reactions promoted by organophosphorus-iron catalysts.

\section{Hydrophosphination}

Selective formation of P-C bonds for the preparation of organophosphorus derivatives is still a topical challenging area of research despite the universality of phosphines in synthetic and catalytic methodologies, ${ }^{2,18-21}$ which usually exhibited an impressive functional group tolerance in comparison to classical routes. ${ }^{22}$

Gaumont and Taillefer reported an interesting regioselective hydrophosphination of styrenes (Scheme 1): ${ }^{23}$ Indeed, the regioselectivity of the $\alpha$ - or $\beta$-phosphinylation of styrenes with diphenylphosphine can be reached by selecting the iron salt $\left(\mathrm{FeCl}_{3}\right.$ or $\mathrm{FeCl}_{2}$, respectively, 30 mol\%). The borane adducts were isolated with 5-87\% yields, after reaction with $\mathrm{BH}_{3} \cdot \mathrm{SMe}_{2}$. The difference of regioselectivity may be due to the difference of Lewis acidity between Fe salts, the Fe(III)-salt generating a polarized and intramolecularly stabilized $\pi$-complex. 
Scheme 1. Regioselective $\alpha$ - and $\beta$-hydrophosphinations of alkenylarenes

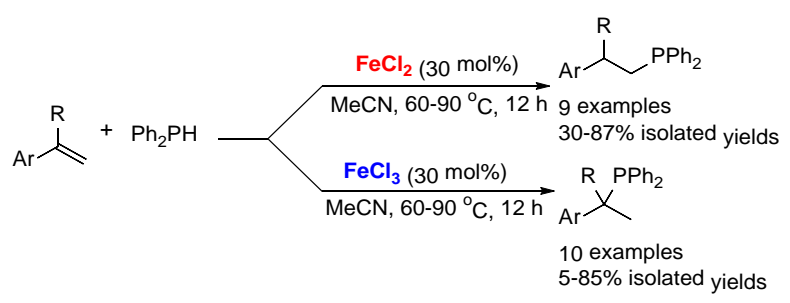

Webster then described Salen-type complexes, Fe-1 $\mathbf{1}^{24-26}$ and the porphyrin $\mu$-oxo complex $\mathbf{F e}-\mathbf{2}^{25}$ in the hydrophosphination of styrene, vinylpyridine and acrylate derivatives performed using Fe$\mathbf{1}$ or Fe-2 (0.5 mol\%) at r.t. leading selectively the anti-Markovnikov adducts (35-98\% yields, Scheme 2).

Scheme 2. Hydrophosphination of alkenes with diphenylphosphine leading to $\mathrm{R}-\mathrm{CH}_{2}-\mathrm{CH}_{2}-\mathrm{PPh}_{2}$

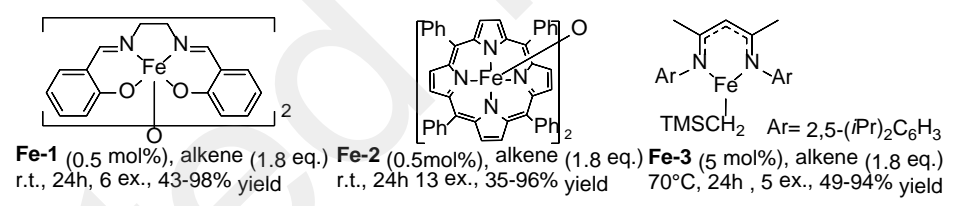

Webster also described the iron(II)- $\beta$-diketiminate Fe-3 (5 mol\%) as a suitable catalyst for the hydrophosphination of activated alkenes at $70^{\circ} \mathrm{C}$ leading to the corresponding tertiary phosphines with an anti-Markonikov selectivity (49-94\% yields). ${ }^{27}$ Notably, less active allylbenzene and 1hexene gave low amounts of phosphines. Additionally, styrene poorly reacted with hindered phosphines or monophosphines.

Waterman found that $\left[\mathrm{CpFe}(\mathrm{CO})_{2}\right]_{2} \mathbf{F e}-4$ (5 mol\%) was efficient for the hydrophosphination of styrene and acrylic derivatives with $\mathrm{Ph}_{2} \mathrm{PH}$ (1 equiv.) under visible light irradiation (LED bulb, 
$\mathrm{hv}>500 \mathrm{~nm})$ at $25-28^{\circ} \mathrm{C}(2-99 \%$ conv. $){ }^{28}$ Under these conditions, styrene led to only $11 \%$ conversion.

Scheme 3. Double hydrophosphination of styrenes

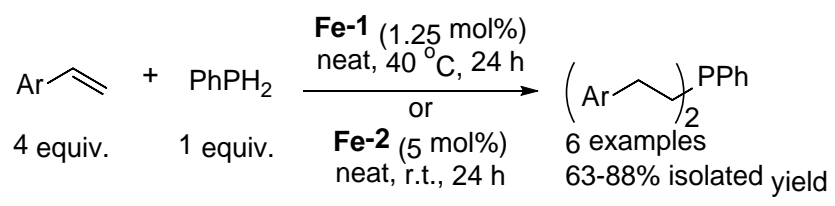

Starting with Fe-1 and Fe-2, the double olefin hydrophosphination reaction of substituted styrenes (4 equiv.) with $\mathrm{PPhH}_{2}$ led to the corresponding tertiary phosphines with 62-96\% yields (Scheme 3). ${ }^{25}$ Interestingly, a two-step sequence was developed to prepare a racemic unsymmetrical tertiary phosphine: the first catalyst free step was performed with $\mathrm{H}_{2} \mathrm{PPh}$ and styrene at $80^{\circ} \mathrm{C}$ leading to secondary phosphines which then reacted with 4-chlorostyrene using Fe-5 (0.5 mol\%) (Scheme 4).

Scheme 4. Preparation of unsymmetrical phosphines.

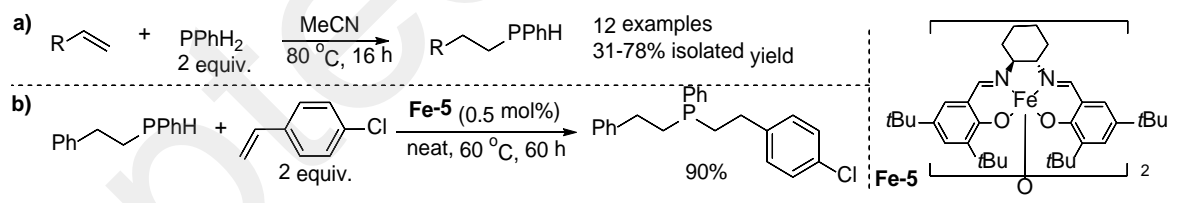

Webster also described the Fe-3 ability to catalyze the first intramolecular hydrophosphination of nonactivated linear phosphinoalkenes leading to phospholanes and phosphinanes, respectively, in $20-86 \%$ yields (Scheme 5 ). ${ }^{29}$

Scheme 5. Phospholane and phosphinane synthesis 


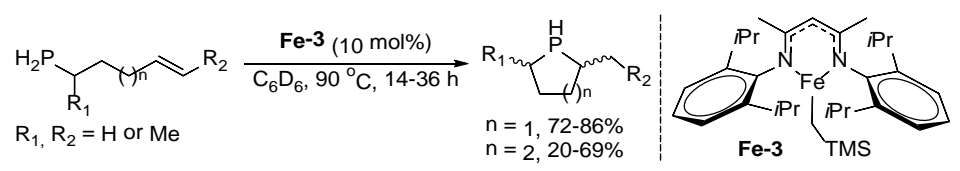

Hydrophosphination of alkynes could be also performed. The first catalytic double hydrophosphination of terminal arylalkynes was reported by Nakazawa (Scheme 6) by reaction with diarylphosphines catalyzed by $\mathrm{CpFe}(\mathrm{CO})_{2} \mathrm{Me}$ (Fe-6, 5 mol\%). ${ }^{30}$ Notably, the reaction proceeded regioselectively with various secondary arylphosphines (2 equiv.) and arylalkynes at $110^{\circ} \mathrm{C}$ to give 1,2-bisphosphinoethane derivatives. In contrast, $n$-(cyclo)hexyl-, benzylacetylene, dicyclohexylphosphine and di-tert-butylphosphine did not undergo hydrophosphination.

Scheme 6. Double hydrophosphination of terminal arylalkynes

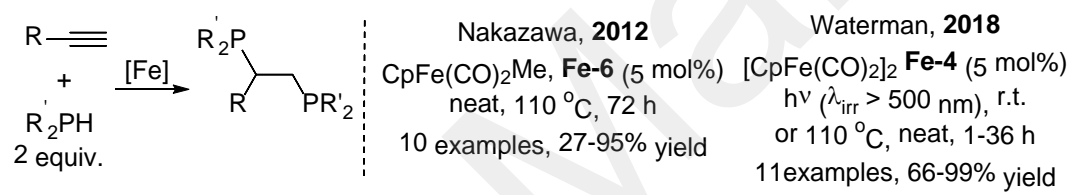

Using $\left[\mathrm{CpFe}(\mathrm{CO})_{2}\right]_{2}$ (5 mol\%, Fe-4), Waterman performed the double hydrophosphination of terminal arylalkynes conducting the reaction with diphenylphosphine under visible-light or thermal conditions (Scheme 6). ${ }^{31}$ The corresponding products were isolated in 66-99\% yields.

The mono-hydrophosphination of terminal arylalkynes with secondary phosphines were also selectively performed by Nakazawa using $\mathrm{Cp} * \mathrm{Fe}(\mathrm{CO})(\mathrm{py})(\mathrm{Me})(\mathbf{F e}-7,10 \mathrm{~mol} \%)$ at $110^{\circ} \mathrm{C}$ (Scheme 7a), yielding to (Z)-vinylphosphines. ${ }^{32}$ The authors proposed a mechanism, involving a $\mathrm{Cp} * \mathrm{Fe}(\mathrm{CO})\left(\mathrm{PPh}_{2}\right)$ active species and the insertion of the coordinated $\mathrm{C} \equiv \mathrm{C}$ bond into the $\mathrm{Fe}-\mathrm{P}$ bond, controlling the regioselectivty. Additionally, using $\mathrm{CpFe}(\mathrm{CO})_{2} \mathrm{Me}$ Fe-6 (5 mol\%), the hydrophosphination of vinyldiarylphosphines led to unsymmetrical 1,2-bis(phosphino)ethanes bearing two different phosphine moieties (Scheme 7b). 
Scheme 7. Synthesis of Z-vinylphosphines and unsymmetric diphosphines

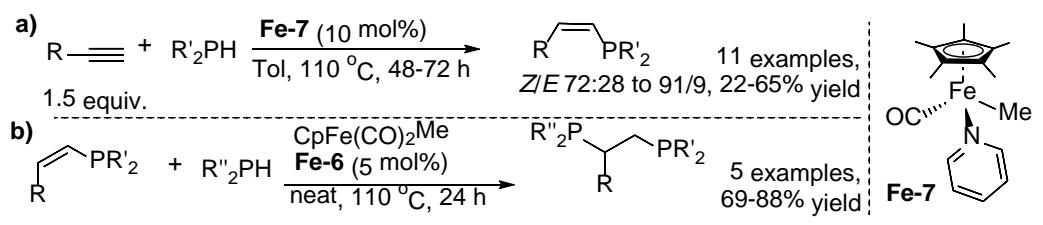

Webster also reported the preparation of vinyl phosphines from terminal (hetero)arylalkynes using Fe-3. Remarkably, the nature of the solvent was crucial on the regioselectivity: Markovnikov-selective products gem-vinylphosphines were obtained at $50^{\circ} \mathrm{C}$ in benzene, whereas Z-selective-anti-Markovnikov products were obtained at $70^{\circ} \mathrm{C}$ in dichloromethane (Scheme 8). ${ }^{33}$ Even if not fully rationalized, preliminary mechanistic studies suggested that the regioselectivities may be linked to the oxidation state of the active species [Fe(II) vs $\mathrm{Fe}(\mathrm{III})]$ and the mode of the C-P bond-forming process.

Scheme 8. Markovnikov vs anti-Markovnikov hydrophosphination

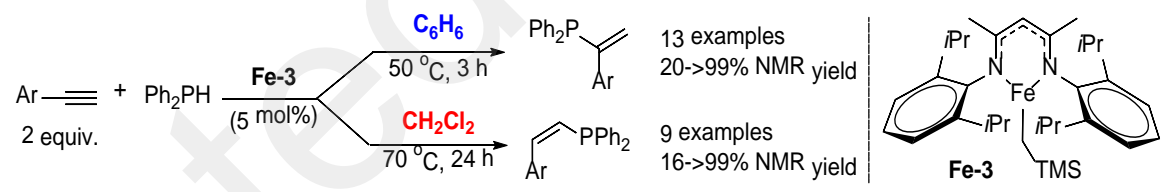

Even if iron-catalyzed hydrophosphination is a growing area of research, with nice chemoselectivities and original regioselectivities, it is still described with limited examples of organophosphorus moieties (mainly $-\mathrm{PPh}_{2}$ and $-\mathrm{PHPh}$ ) and the stereoselective preparation of chiral phosphines is still a challenging point to be solved.

\section{Hydrosilylation}

The catalyzed hydrosilylation of olefins is an important research area in academy and industry for the production of alkylsilanes, starting materials for high value silicon-based materials.,34 
Thus, there are numerous methods to perform hydrosilylation using noble transition metal complexes such as Speier ${ }^{35}\left[\mathrm{H}_{2} \mathrm{PtCl}_{6}\right] \cdot 6 \mathrm{H}_{2} \mathrm{O}$ and Karstedt ${ }^{36-37}\left[\mathrm{Pt}_{2}\left(\mathrm{Me}_{2} \mathrm{SiCH}=\mathrm{CH}_{2}\right)_{2} \mathrm{O}\right]_{3}$ catalysts. With iron, the pioneering report published in 1962 by Nesmeyanov described the reaction of alkenes with hydrosilanes in the presence of $\mathrm{Fe}(\mathrm{CO})_{5}$ or colloidal iron catalysts, leading to mixtures of alkyl- and vinyl-silanes. ${ }^{38}$ Using $\mathrm{Fe}_{2}(\mathrm{CO})_{9}$, the reaction of styrene with triethylsilane led specifically to $(E)-\mathrm{Ph}-\mathrm{CH}=\mathrm{CH}-\mathrm{SiEt}_{3}$, resulting from dehydrogenative hydrosilylation. ${ }^{39}$

During the last decades, iron catalyzed hydrosilylations of olefins have seen an increasing interest. Noticeably, iron in association with organophosphorus ligands led to efficient catalysts. $^{2,40}$ Based on the breakthrough made by Chirik with bisiminopyridine-Fe complexes (e.g. Fe-8) highly efficient in olefin hydrosilylation, ${ }^{41-42}$ mixed structures bearing iminopyridine or bipyridine moieties and organophosphorus motifs were designed. Thus, Huang described pincer complexes having a phosphinite-iminopyridine skeleton and demonstrated their efficiency in chemoselective hydrosilylation of functionalized olefins. ${ }^{43}$ Indeed, the catalyst (1.0 mol\%) generated from (Fe-9a) and $\mathrm{NaBHEt}_{3}$ hydrosilylated numerous olefins with $\mathrm{PhSiH}_{3}$ or $\mathrm{Ph}_{2} \mathrm{SiH}_{2}$ (1.0 equiv., $23^{\circ} \mathrm{C}, 3 \mathrm{~h}$ ). This catalytic system exhibited good functional tolerance (ketones, esters, amides). Interestingly, no reaction occurred with internal alkenes and styrenes (Scheme 9). It should be underlined the divergent selectivity in the challenging hydrosilylation of unsaturated ketones (e.g. 5-hexen-2-one). Whereas with Chirik's complex Fe-8, the ketone was selectively reduced with diphenylsilane, the chemoselectivity was reversed using Fe-9a with the hydrosilylation of the $\mathrm{C}=\mathrm{C}$ bond.

Scheme 9. Unsymmetrical pincer-iron complexes for hydrosilylation of terminal alkenes leading to linear alkylsilanes 


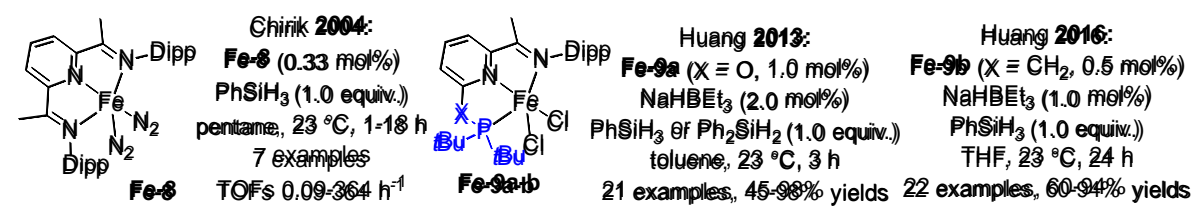

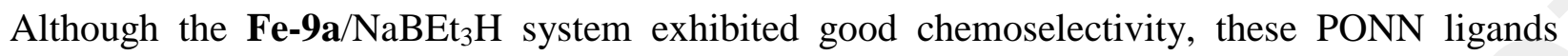
were prone to degradation via P-O bond cleavage. Thus, Huang prepared more robust phosphineiminopyridine catalysts (Fe-9b, Scheme 9), ${ }^{44}$ and evaluated them in hydrosilylation of alkenes leading to linear products in good yields and regioselectivities (linear/branched up to >99:1). Notably, lowering the catalytic loading to $0.02 \mathrm{~mol} \%$ of $\mathbf{F e}-9 \mathbf{b} / \mathrm{NaBEt}_{3} \mathrm{H}$ (1:4), the hydrosilylation of 1-octene with $\mathrm{PhSiH}_{3}$ exhibited a TON=3950, which was significantly more active than Fe-9a.

Scheme 10. PNN-pincer-iron complexes for hydrosilylation of alkenes

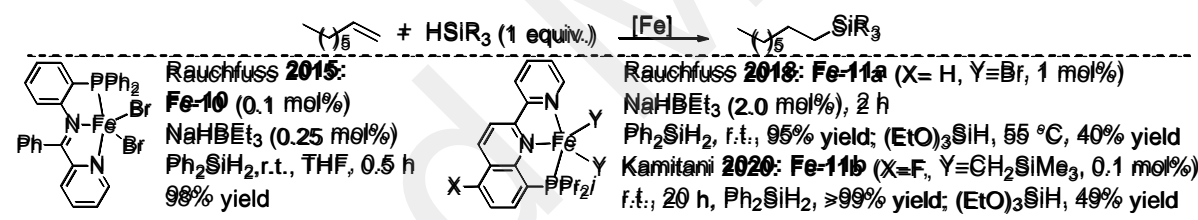

Similarly, Rauchfuss reported catalytic systems from phosphine-iminopyridine complexes (e.g. Fe-10 $)^{45}$ and $\mathrm{NaBEt}_{3} \mathrm{H}(0.1$ mol\%) for selective anti-Markovnikov addition of 1-octene or vinylpentamethyldisiloxane with diphenylsilane. Fe-11a was also employed for the hydrosilylation of 1-octene with $\mathrm{Ph}_{2} \mathrm{SiH}_{2}$ (Scheme 10). ${ }^{46}$ Additionally, hydrosilylation was performed with triethoxysilane at $55^{\circ} \mathrm{C}$, with a lower selectivity due to isomerization to 2-octene. Similarly, Kamitani described an even more active pre-catalyst ( $\mathrm{PNN}) \mathrm{Fe}\left(\mathrm{CH}_{2} \mathrm{SiMe}_{3}\right)_{2} \mathbf{F e}-\mathbf{1 1 b}$ for hydrosilylation of terminal alkenes. Remarkably, hydrosilylation of 1-octene with phenylsilane led to the anti-Markovnikov phenylsilyloctane with TON and TOF up to 480,000 and 10,000 $\mathrm{h}^{-1}$, respectively, (catalytic loading as low as $0.0001 \mathrm{~mol} \%) .{ }^{47}$ Notably, these values are the highest 
observed for iron catalyzed hydrosilylation of olefins, even if far away for the efficiency of platinum based Karstedt catalyst.

Vinylsilanes are versatile synthetic building blocks in molecular synthesis. ${ }^{48}$ One of the efficient access to such compounds is the hydrosilylation of alkynes. Using $\left[\mathrm{Fe}(\mathrm{H})(\mathrm{CO})(\mathrm{NO})\left(\mathrm{PPh}_{3}\right)_{2}\right](\mathbf{F e}-$ 13), Plietker performed stereoselective hydrosilylations of internal alkynes to vinylsilanes (Scheme 11). ${ }^{49}$ Of particular interest, the nature of the hydrosilane had a crucial effect on the selectivity $E$ vs Z. Indeed, with Fe-13 (1 mol\%) and trimethylamine (50 mol\%), diphenylacetylene reacted with a primary silane to conduct selectively to $Z$-vinylsilanes ( $E / Z$ up to $1 / 20$; yields up to $98 \%$ ). With tertiary silanes, the reverse stereoselectivity was obtained ( $E / Z$ ratio of $>20: 1$ and yields up to $97 \%$ ). The regioselectivity can also be managed by the nature of internal alkynes: for example, $E$-vinylsilane was generated from dialkylacetylene whatever the hydrosilane $\left[\mathrm{PhSiH}_{3}\right.$ or $\left.\mathrm{Ph}(\mathrm{Me})\left(\mathrm{CH}=\mathrm{CH}_{2}\right) \mathrm{Si}-\mathrm{H}\right]$.

Scheme 11. Stereoselective reduction of internal alkynes

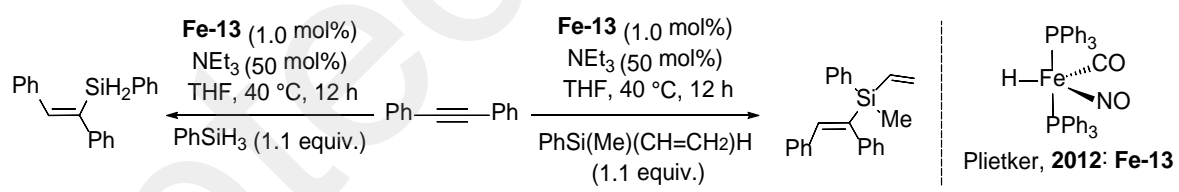

Zhan reported the anti-Markovnikov hydrosilylation of terminal aryl- and alkyl-alkynes leading specifically to (E)- $\beta$-vinylsilanes, using an in situ catalyst from $\mathrm{FeCl}_{2}$ (2 mol\%), Xantphos (2 mol\%) and $\mathrm{NaHBEt}_{3}$ (4 mol\%), with phenylsilane (1.1 equiv.) at $50^{\circ} \mathrm{C}$ (Scheme 12). Notably, internal $\mathrm{C}=\mathrm{C}$, cyclopropyl, tosylate, cyano groups were tolerated. ${ }^{50}$

Scheme 12. Hydrosilylation of terminal alkynes 


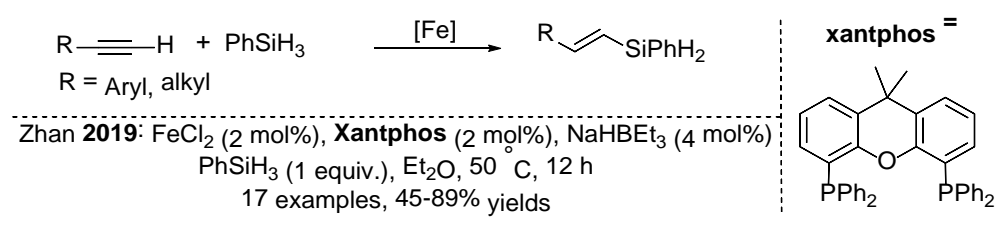

Despite the progress made and the huge variety of silanes used, in terms of the application for the production of organosilanes in fine and bulk synthesis, iron is still overshadowed by the traditional noble-metal catalysts in terms of reactivity, selectivity and diversity.

\section{Hydroborylation}

Organoborane derivatives are of importance in synthesis, with an increasing use since the discovery of Suzuki cross-coupling reactions. Among the main methodologies of preparation, the catalyst-free or metal-catalyzed selective hydroboration of alkenes and alkynes are usually efficient and sustainable pathways. ${ }^{51-52}$ In the area of transition metal catalyzed hydroboration, by contrast with organoborane, organoboronate is an interesting class of compounds. ${ }^{53-56}$ Nowadays, Rhodium is far away the metal of choice for this reaction, ${ }^{57-58}$ and examples with iron are scarce. Following the pioneering results of Ritter on diene, ${ }^{59}$ Huang reported an efficient catalyst, prepared from the bipyridyl-phosphine complex (Fe-14, 0.25-5.0 mol\%) and $\mathrm{NaHBEt}_{3}$ (0.75-15 mol\%), for the hydroborylation of terminal alkenes with HBpin (0.5 equiv.) at r.t. leading to alkylboronates in 62-96\% yields (Scheme 13). ${ }^{60}$

Scheme 13. Hydroborylation of terminal alkenes

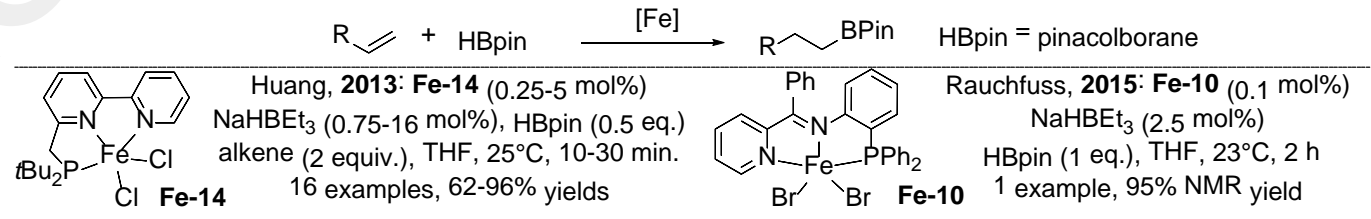


Noticeably, this hydroborylation was efficiently conducted with linear terminal alkenes and tolerated tosylate, amines, benzylethers, acetals and internal $\mathrm{C}=\mathrm{C}$ bond. With styrenes, using Fe14 (2.0 mol\%) and $\mathrm{NaHBEt}_{3}(6.0 \mathrm{~mol} \%)$ at $25^{\circ} \mathrm{C}$, a mixture of products resulting from hydroborylation, dehydrogenative borylation and hydrogenation was obtained. If adding acetonitrile (20-40 mol\%), the hydroborylation product was selectively obtained in $78-96 \%$ yields. The quantity of acetonitrile was crucial: when conducted in acetonitrile, only $5 \%$ of the hydroborated derivative was found. A mechanism was proposed (Scheme 14): after reduction of Fe-14 by $\mathrm{NaHBEt}_{3}$ then coordination of the olefin and oxidative addition of H-Bpin, the species (II-2) was generated. The insertion of the $\mathrm{C}=\mathrm{C}$ into the Fe-H bond led to the alkylboryl iron (II3), which produced the linear boronate via a final reductive elimination.

Scheme 14. Mechanism for hydroborylation of alkenes.

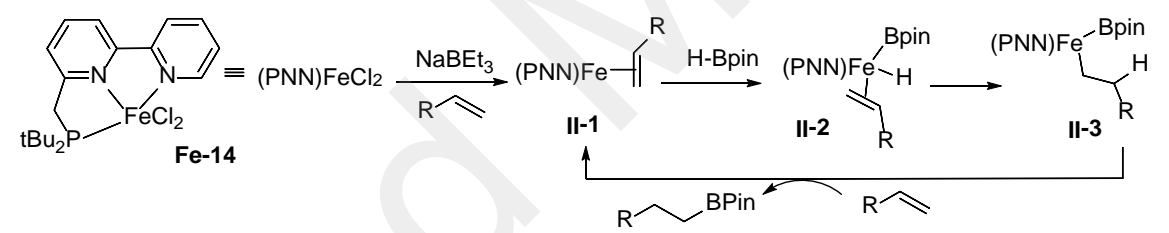

Rauchfuss reported another efficient catalyst prepared from phosphine-iminopyridine complex (Fe-10, $0.1 \mathrm{~mol} \%)$ and $\mathrm{NaHBEt}_{3}(0.25 \mathrm{~mol} \%)$ for the hydroborylation of 1-octene with HBpin (1.0 equiv.) at r.t. (Scheme 13). ${ }^{45}$

Using a $\mathrm{N}$-phosphinoamidinate complex (Fe-15), the isomerization/hydroborylation of internal alkenes leading to linear terminal alkyl diazaborolanes was reported (Scheme 15). Interestingly, 1,3-dimethyl-1,3-diaza-2-boracyclopentane gave better results than HBpin. ${ }^{61}$

Scheme 15. Isomerization/hydroborylation of internal olefins 


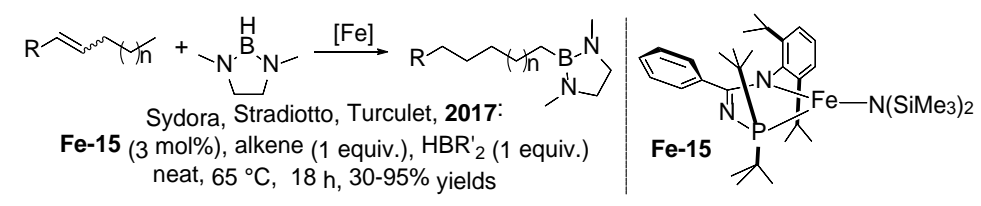

Nishibayashi demonstrated that the diphosphinopyrrolide complex (Fe-16, 1.0 mol\%) was active in hydroboration of terminal alkynes with HBpin (1.1 equiv.) at r.t. leading selectively to the $E$ vinylboronates in 84-94\% yields (Scheme 16). ${ }^{62}$ Nevertheless, the reactivity was inhibited using hindered alkynes, and lowered with internal alkynes. Using $0.1 \mathrm{~mol} \%$ of $\mathbf{F e - 1 6}$, at $60^{\circ} \mathrm{C}$, TONs up to 710 were obtained.

Scheme 16. Hdroboration of alkynes

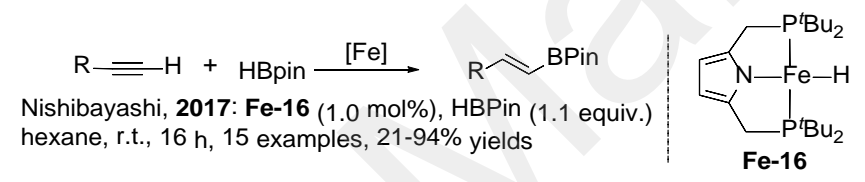

Interestingly, the modification of the structure of the iron complex have a strong influence on the transformation stereoselectivity as described by Kirchner using the $\left[\mathrm{Fe}(\mathrm{PNP})(\mathrm{H})_{2}\left(\eta^{2}-\mathrm{H}_{2}\right)\right]$ complex (Fe-17, 0.4-4.0 mol\%): the hydroboration of terminal alkynes with pinacolborane (1.1 equiv.) at r.t. conducted to vinylboronates with high Z-selectivity (Scheme 17). ${ }^{63}$ The transformation was then rationalized via a Fe-C/H-B $\sigma$-bond metathesis followed by the selective syn insertion of the resulting coordinated alkynylboronate into the formed iron-hydride bond, thus explaining the (Z)-stereoselectivity. ${ }^{64}$

Scheme 17. Z-Hydroboration of alkynes

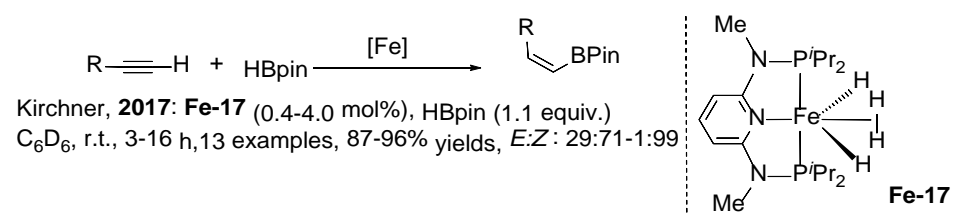


Another attractive pathway to access to vinyl boronate esters is the catalytic dehydrogenative borylation of styrenes, ${ }^{65}$ scarcely reported at iron. $\mathrm{Ge}^{66}$ described such transformation using $\mathrm{Fe}\left(\mathrm{PMe}_{3}\right)_{4}(\mathbf{F e}-\mathbf{1 8}, 3.0-5.0$ mol\%), in the presence of mono- and di-substituted vinylarenes, HBpin (0.83 equiv.) and norbornene (2.0 equiv.) at $50^{\circ} \mathrm{C}$. The resulting $E$-vinyl-boronate esters were obtained in $60-94 \%$ yields with a good group tolerance (imines, amino, boronate, $\mathrm{Ph}_{2} \mathrm{P} \ldots$ ). The use of norbornene as hydrogen acceptor was crucial for the reaction selectivity (Scheme 18). ${ }^{66}$

Scheme 18. Dehydrogenative borylation of alkenes

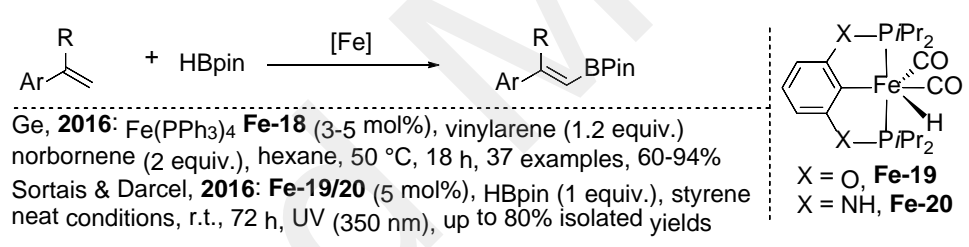

Simultaneously, our group has shown that PCP-iron-hydride complexes (Fe-19-20, 5 mol\%), were selective for the dehydrogenative borylation of styrene, ${ }^{67}$ using HBpin (1 equiv.), without hydrogen scavenger at r.t., under UV-irradiation, leading to the vinylboronate ester with up to $80 \%$ yield (Scheme 18). ${ }^{67}$

Noticeably, the performance obtained by Nishibayashi (TON up to 700) is among the best obtained at iron and has to be placed in perspective with the one reported by Thomas using a bis(imimo)pyridine iron catalyst (TOF up to $30,000 \mathrm{~h}^{-1}$ ). ${ }^{68}$ Nevertheless, one notable limitation of the known iron catalysts is the lack of catalytic activity for hydroboration of internal alkenes and alkynes. 


\section{Hydromagnesiation}

Grignard reagents are one of the class of organometallic derivatives of great importance in molecular synthesis thanks to their availability, ease of handling and impressive reactivity. ${ }^{69}$ They are obtained (i) by mixing the alkylhalide with magnesium or (ii) by magnesium-halide exchange of a organohalide with AlkylMgX. ${ }^{70}$ Noteworthy, the hydromagnesiation may provide an interesting alternative to the traditional techniques. It is thus consisting in a Grignardalkene/alkyne exchange via a metal catalyzed $\beta$-elimination affording the alkyl or vinyl Grignard reagents. $^{71-72}$

At iron, after the pioneering contributions of Cooper, Finkbeiner, and Kochi, ${ }^{72-75}$ Shirakawa and Hayashi described the hydromagnesiation of olefins with a Grignard reagent using a catalytic system associating tributylphosphine (10 mol\%), $\mathrm{FeCl}_{3}$ (2.5 mol\%) and $\mathrm{CuBr}$ (5 mol\%) (Scheme 19). ${ }^{76}$ The exchange between terminal olefins and cyclopentylmagnesium bromide led to linear Grignard reagents in high yields, and cyclopentene, which could not be hydromagnesiated, thus making the reaction irreversible, and the cyclopentylmagnesium bromide, the reagent of choice. The obtained 1-alkylmagnesium halides could then react with various electrophiles.

Scheme 19. Hydromagnesiation of alkenes

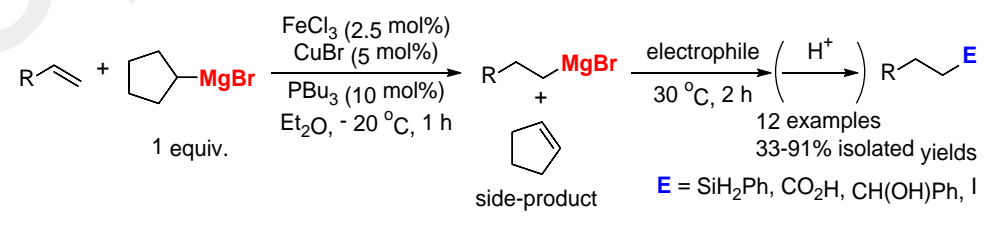

The alkylmagnesiation was also extended to alkynes. Using a similar catalytic system (5 mol\% $\mathrm{Fe}(\text { aсас) })_{3}, 10 \mathrm{~mol} \% \mathrm{CuBr}, 40 \mathrm{~mol} \% \mathrm{PBu}_{3}$ ), arylmagnesium halides (2 equiv.) could react with internal alkynes at $60^{\circ} \mathrm{C}$ to produce after hydrolysis the trisubstituted olefins in $36-90 \%$ yields 
and E/Z-selectivity up to $97: 3 .^{77}$ To promote the reaction of 1-alkyl Grignard reagents with internal alkynes, a modified catalytic system was used [Fe(acac) 3 (5 mol\%), CuBr (10 mol\%), $\mathrm{PBu}_{3}$ (20 mol\%), and TMEDA] leading to $\beta$-alkylvinylmagnesium reagents, then the corresponding tri-substituted alkenes in 57-93\% yields after methanolysis (Scheme 20). ${ }^{76}$ By contrast, dialkylacetylenes were unreactive.

Scheme 20. Alkylmagnesiation of alkynes

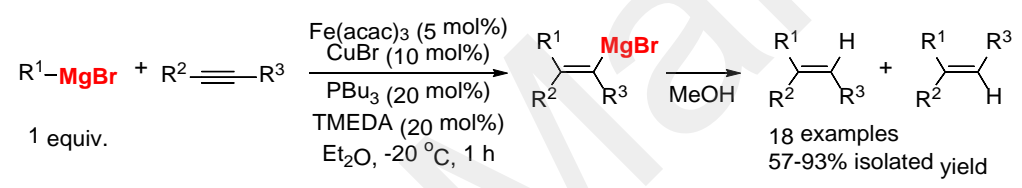

Using this iron/copper catalytic system, a sequential reaction involving the alkene-Grignard exchange then the alkylmagnesiation of internal alkynes were conducted by adding 1phenyloctyne to the reaction mixture obtained from 1-hexene and cyclopentylmagnesium bromide and $79 \%$ of the tri-substituted alkene was isolated (Scheme 21). It was proposed that iron promoted the hydrometalation step, and the copper assisted the transmetalation step from iron to magnesium. ${ }^{76}$

Scheme 21. One-pot synthesis of tri-substituted alkenes

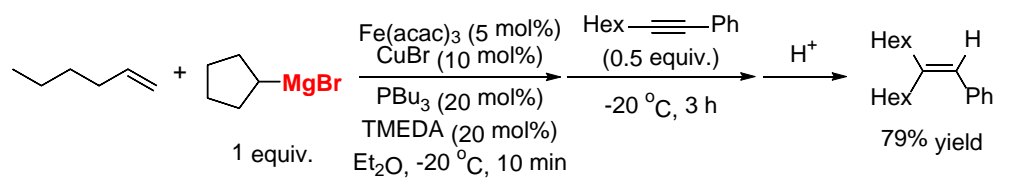


Overall, these hydromagnesiation reactions paved the way to extend this strategy for the easy in-situ preparation of other organometallic reagents from zinc, aluminum...

In summary, among the variety of ligands associated to iron able to perform efficiently catalytic transformations, the combination with organophosphorus, mainly arylphosphines, provides versatile catalysts, particularly for hydrometalation of olefins and alkynes. The fine design of the organophosphorus iron complexes led to divergent chemo-, regio- or stereo-selectivities in comparison with other families of iron catalysts, as highlighted in hydrosilylation and hydroborylation areas. A special focus was also made on iron-catalyzed hydrophosphination leading selectively to alkyl- and alkenyl-phosphines. Such reaction constitutes an interesting and powerful tool for the synthesis of organophosphorus derivatives, even if the diversity of the phosphorus substituents has still to be enlarged. Iron-catalyzed hydromagnesiation is another exciting area of research; even if discovered in the 60's, it has emerged since only less than a decade.

There are still interesting challenges associated to iron-catalyzed hydrometalation, including hydromagnesiation, hydrozincation or hydroalumination leading to the preparation of synthetically valuable organometallic reagents. The chiral version of hydroborylation, hydrosilylation and hydrophosphination is another quite virgin area to be developed. The study of iron-phosphine based catalysts is thus believed to be a promising area of research and more new reactivity should be reported in the near future.

\section{AUTHOR INFORMATION}

\section{Corresponding Author}

*E-mail: christophe.darcel@univ-rennes1.fr 


\section{ORCID}

Duo Wei: 0000-0002-5928-3151

Christophe Darcel: 0000-0001-6711-5978

\section{Notes}

The authors declare no competing financial interest.

\section{Biographies}

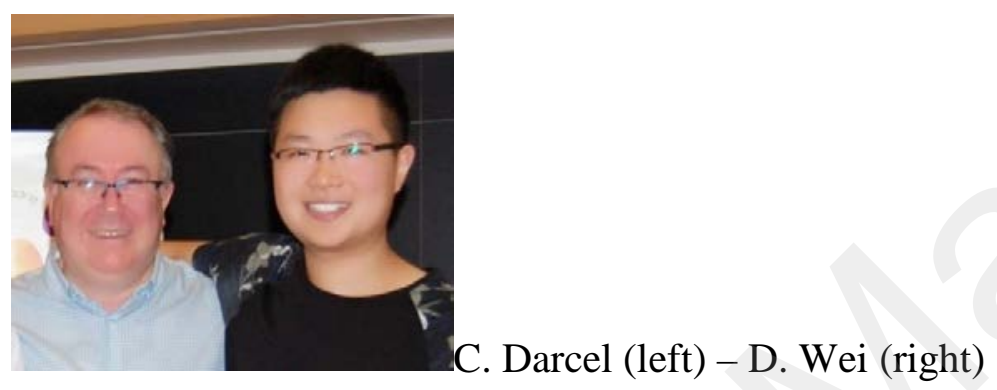

Duo Wei was born in Hebei Province, P.R. China, in 1991. After receiving his B.Sc. degree in 2014 from Zhejiang Sci-Tech University under the supervision of Prof. X.-F. Wu, he then obtained his Master's (2016) and Ph.D. (2019) degrees in chemistry from the Université de Rennes 1 (France) under the supervision of Prof. Christophe Darcel and Prof. Jean-Baptiste Sortais. He is currently a postdoctoral fellow in the group of Prof. Matthias Beller at LIKAT Rostock (Germany). His work focuses on the organometallic catalysis in reduction and dehydrogenation reactions.

Prof. Christophe Darcel grew up in the north cost of Britany and studied chemistry at the Université de Rennes 1, where he was awarded his $\mathrm{PhD}$ in 1995 working under the supervision of Dr. C. Bruneau and Prof. P. H. Dixneuf. He first spent one year as a postdoctoral fellow in Geneva (Switzerland) with Prof. W. Oppolzer, and then obtained a Humboldt fellowship and 
joined Prof. P. Knochel's group in Marburg (Germany). He was then appointed at the Université de Cergy-Pontoise, and at the Université de Bourgogne, Dijon as associate professor, and finally at the Université de Rennes 1 since 2007 as full professor. His current research interests focus on homogeneous catalysis using non noble metals, with particular emphasis on well-defined iron catalysts.

\section{ACKNOWLEDGMENT}

We gratefully acknowledge funding from the University de Rennes 1, the Centre National de la Recherche Scientifique (CNRS), the CNRS Federation Increase.

\section{REFERENCES}

(1) Bauer, I.; Knölker, H.-J. Iron Catalysis in Organic Synthesis. Chem. Rev. 2015, 115, 3170-3387.

(2) Misal Castro, L. C.; Li, H.; Sortais, J.-B.; Darcel, C. When Iron Met Phosphines: a Happy Marriage for Reduction Catalysis. Green Chem. 2015, 17, 2283-2303.

(3) Wei, D.; Darcel, C. Iron Catalysis in Reduction and Hydrometalation Reactions. Chem. Rev. 2019, 119, 2550-2610.

(4) Greenhalgh, M. D.; Jones, A. S.; Thomas, S. P. Iron-Catalyzed Hydrofunctionalisation of Alkenes and Alkynes. ChemCatChem 2015, 7, 190-222.

(5) Chen, J.; Guo, J.; Lu, Z. Recent Advances in Hydrometallation of Alkenes and Alkynes via the First Row Transition Metal Catalysis. Chin. J. Chem . 2018, 36, 1075-1109.

(6) Bolm, C.; Legros, J.; Le Paih, J.; Zani, L. Iron-Catalyzed Reactions in Organic Synthesis. Chem. Rev. 2004, 104, 6217-6254.

(7) Plietker, B. Iron Catalysis: Fundamentals and Applications; Springer-Verlag: Berlin Heidelberg, 2011; Vol. 33.

(8) Junge, K.; Schröder, K.; Beller, M. Homogeneous Catalysis Using Iron Complexes: Recent Developments in Selective Reductions. Chem. Commun. 2011, 47, 4849-4859.

(9) Riener, K.; Haslinger, S.; Raba, A.; Högerl, M. P.; Cokoja, M.; Herrmann, W. A.; Kühn, F. E. Chemistry of Iron $N$-Heterocyclic Carbene Complexes: Syntheses, Structures, Reactivities, and Catalytic Applications. Chem. Rev. 2014, 114, 5215-5272.

(10) Ollevier, T.; Keipour, H. Enantioselective Iron Catalysts. In Iron Catalysis II; Bauer, E., Ed.; Springer-Verlag: Berlin, 2015; Vol. 50, p 259-309.

(11) Nakajima, Y.; Shimada, S. Hydrosilylation Reaction of Olefins: Recent Advances and Perspectives. RSC Adv. 2015, 5, 20603-20616.

(12) Xinwei, H.; Xiaoqian, H.; Jiajia, T.; Guang, H.; Yongjia, S. Progress in Iron ComplexesCatalyzed Organic Reactions. Chin. J. Org. Chem. 2016, 36, 1465-1483. 
(13) Renaud, J.-L.; Gaillard, S. Recent Advances in Iron- and Cobalt-Complex-Catalyzed Tandem/Consecutive Processes Involving Hydrogenation. Synthesis 2016, 48, 36593683.

(14) Ananikov, V. P.; Tanaka, T. Hydrofunctionalization; Springer: Heidelberg, 2013.

(15) Nakajima, Y.; Shimada, S. Hydrosilylation Reaction of Olefins; Recent Advances and Perspectives. RSC Adv. 2015, 5, 20603-20616.

(16) Wen, H.; Liu, G.; Huang, Z. Recent Advances in Tridentate Iron and Cobalt Complexes for Alkene and Alkyne Hydrofunctionalizations. Coord. Chem. Rev. 2019, 386, 138-153.

(17) Trost, B. M.; Ball, Z. T. Addition of Metalloid Hydrides to Alkynes: Hydrometallation with Boron, Silicon and Tin. Synthesis 2005, 853-887.

(18) Fleming, J. T.; Higham, L. J. Primary Phosphine Chemistry. Coord. Chem. Rev. 2015, 297-298, 127-145.

(19) Nell, B. P.; Tyler, D. R. Synthesis, Reactivity, and Coordination Chemistry of Secondary Phosphines. Coord. Chem. Rev. 2014, 279, 23-42.

(20) Bezzenine-Lafollée, S.; Gil, R.; Prim, D.; Hannedouche, J. First-Row Late Transition Metals for Catalytic Alkene Hydrofunctionalisation: Recent Advances in C-N, C-O and C-P Bond Formation. Molecules 2017, 22, 1901.

(21) Delacroix, O.; Gaumont, A. Hydrophosphination of Unactivated Alkenes, Dienes and Alkynes: a Versatile and Valuable Approach for the Synthesis of Phosphines. Curr. Org. Chem. 2005, 9, 1851-1882.

(22) Wauters, I.; Debrouwer, W.; Stevens, C. V. Preparation of Phosphines through C-P Bond Formation. Beilstein J. Org. Chem. 2014, 10, 1064-1096.

(23) Routaboul, L.; Toulgoat, F.; Gatignol, J.; Lohier, J.-F.; Norah, B.; Delacroix, O.; Alayrac, C.; Taillefer, M.; Gaumont, A.-C. Iron-Salt-Promoted Highly Regioselective $\alpha$ and $\beta$ Hydrophosphination of Alkenyl Arenes. Chem. Eur. J. 2013, 19, 8760-8764.

(24) Gallagher, K. J.; Webster, R. L. Room Temperature Hydrophosphination Using a Simple Iron Salen Pre-catalyst. Chem. Commun. 2014, 50, 12109-12111.

(25) Gallagher, K. J.; Espinal-Viguri, M.; Mahon, M. F.; Webster, R. L. A Study of Two Highly Active, Air-Stable Iron(III)- $\mu$-Oxo Precatalysts: Synthetic Scope of Hydrophosphination using Phenyl- and Diphenylphosphine. Adv. Synth. Catal. 2016, 358, 2460-2468.

(26) Espinal-Viguri, M.; Mahon, M. F.; Tyler, S. N. G.; Webster, R. L. Iron Catalysis for the Synthesis of Ligands: Exploring the Products of Hydrophosphination as Ligands in Cross-coupling. Tetrahedron 2017, 73, 64-69.

(27) King, A. K.; Buchard, A.; Mahon, M. F.; Webster, R. L. Facile, Catalytic Dehydrocoupling of Phosphines Using $\beta$-Diketiminate Iron(II) Complexes. Chem. Eur. J. 2015, 21, 15960-15963.

(28) Pagano, J. K.; Bange, C. A.; Farmiloe, S. E.; Waterman, R. Visible Light Photocatalysis Using a Commercially Available Iron Compound. Organometallics 2017, 36, 3891-3895.

(29) Espinal-Viguri, M.; King, A. K.; Lowe, J. P.; Mahon, M. F.; Webster, R. L. Hydrophosphination of Unactivated Alkenes and Alkynes Using Iron(II): Catalysis and Mechanistic Insight. ACS Catal. 2016, 6, 7892-7897.

(30) Kamitani, M.; Itazaki, M.; Tamiya, C.; Nakazawa, H. Regioselective Double Hydrophosphination of Terminal Arylacetylenes Catalyzed by an Iron Complex. J. Am. Chem. Soc. 2012, 134, 11932-11935. 
(31) Ackley, B. J.; Pagano, J. K.; Waterman, R. Visible-light and Thermal Driven Double Hydrophosphination of Terminal Alkynes Using a Commercially Available Iron Compound. Chem. Commun. 2018, 54, 2774-2776.

(32) Itazaki, M.; Katsube, S.; Kamitani, M.; Nakazawa, H. Synthesis of Vinylphosphines and Unsymmetric Diphosphines: Iron-catalyzed Selective Hydrophosphination Reaction of Alkynes and Vinylphosphines with Secondary Phosphines. Chem. Commun. 2016, 52, 3163-3166.

(33) King, A. K.; Gallagher, K. J.; Mahon, M. F.; Webster, R. L. Markovnikov versus antiMarkovnikov Hydrophosphination: Divergent Reactivity Using an Iron(II) $\beta$ Diketiminate Pre-Catalyst. Chem. Eur. J. 2017, 23, 9039-9043.

(34) Du, X.; Huang, Z. Advances in Base-Metal-Catalyzed Alkene Hydrosilylation. ACS Catal. 2017, 7, 1227-1243.

(35) Speier, J. L. Homogeneous Catalysis of Hydrosilation by Transition Metals. In Adv. Organomet. Chem.; Stone, F. G. A., West, R., Eds.; Elsevier, 1979; Vol. 17, p 407-447.

(36) Karstedt, B. US Patent 3715 334. 1973.

(37) Hitchcock, P. B.; Lappert, M. F.; Warhurst, N. J. Synthesis and Structure of a racTris(divinyldisiloxane) diplatinum(0) Complex and its Reaction with Maleic Anhydride. Angew. Chem. Int. Ed. 1991, 30, 438-440.

(38) Nesmeyanov, A.; Freidlina, R. K.; Chukovskaya, E.; Petrova, R.; Belyavsky, A. Addition, Substitution, and Telomerization Reactions of Olefins in The Presence of Metal Carbonyls or Colloidal Iron. Tetrahedron 1962, 17, 61-68.

(39) Kakiuchi, F.; Tanaka, Y.; Chatani, N.; Murai, S. Completely Selective Synthesis of (E)$\beta$-(Triethylsilyl)styrenes by $\mathrm{Fe}_{3}(\mathrm{CO})_{12}$-Catalyzed Reaction of Styrenes with Triethylsilane. J. Organomet. Chem. 1993, 456, 45-47.

(40) Zhang, M.; Zhang, A. Iron-catalyzed Hydrosilylation Reactions. Appl. Organomet. Chem. 2010, 24, 751-757.

(41) Tondreau, A. M.; Atienza, C. C. H.; Weller, K. J.; Nye, S. A.; Lewis, K. M.; Delis, J. G. P.; Chirik, P. J. Iron Catalysts for Selective Anti-Markovnikov Alkene Hydrosilylation Using Tertiary Silanes. Science 2012, 335, 567-570.

(42) Bart, S. C.; Lobkovsky, E.; Chirik, P. J. Preparation and Molecular and Electronic Structures of Iron(0) Dinitrogen and Silane Complexes and their Application to Catalytic Hydrogenation and Hydrosilation. J. Am. Chem. Soc. 2004, 126, 13794-13807.

(43) Peng, D.; Zhang, Y.; Du, X.; Zhang, L.; Leng, X.; Walter, M. D.; Huang, Z. PhosphiniteIminopyridine Iron Catalysts for Chemoselective Alkene Hydrosilylation. J. Am. Chem. Soc. 2013, 135, 19154-19166.

(44) Du, X.; Zhang, Y.; Peng, D.; Huang, Z. Base-Metal-Catalyzed Regiodivergent Alkene Hydrosilylations. Angew. Chem. Int. Ed. 2016, 55, 6671-6675.

(45) Gilbert-Wilson, R.; Chu, W.-Y.; Rauchfuss, T. B. Phosphine-Iminopyridines as Platforms for Catalytic Hydrofunctionalization of Alkenes. Inorg. Chem. 2015, 54, 5596-5603.

(46) Basu, D.; Gilbert-Wilson, R.; Gray, D. L.; Rauchfuss, T. B.; Dash, A. K. Fe and Co Complexes of Rigidly Planar Phosphino-Quinoline-Pyridine Ligands for Catalytic Hydrosilylation and Dehydrogenative Silylation. Organometallics 2018, 37, 2760-2768.

(47) Kamitani, M.; Kusaka, H.; Yuge, H. Development of Activator-free Iron Pincer Complexes for Alkene Hydrosilylation and Elucidation of Its Activation Mechanism. Chem. Lett. 2019, 48, 1196-1198. 
(48) Luh, T. Y.; Liu, S. T. Synthetic Applications of Allylsilanes and Vinylsilanes. In PATAI'S Chemistry of Functional Groups, 2009.

(49) Belger, C.; Plietker, B. Aryl-Aryl Interactions as Directing Motifs in the Stereodivergent Iron-Catalyzed Hydrosilylation of Internal Alkynes. Chem. Commun. 2012, 48, 54195421.

(50) Liu, Z.-K.; Zhang, G.-L.; Li, D.-C.; Yang, Y.; Chen, L.; Zhan, Z.-P. Iron-Catalyzed Synthesis of $(E)-\beta$-Vinylsilanes via a Regio-and Stereoselective Hydrosilylation from Terminal Alkynes. Synlett 2019, 30, 235-239.

(51) Burgess, K.; Ohlmeyer, M. J. Transition-Metal Promoted Hydroborations of Alkenes, Emerging Methodology for Organic Transformations. Chem. Rev. 1991, 91, 1179-1191.

(52) Miyaura, N. Hydroboration, Diboration, Silylboration, and Stannylboration. In Catalytic Heterofunctionalization; Togni, A., Grützmacher, H., Eds.; Wiley-VCH Verlag GmbH: Weinheim, 2001, p 1-45.

(53) Doucet, H. Suzuki-Miyaura Cross - Coupling Reactions of Alkylboronic Acid Derivatives or Alkyltrifluoroborates with Aryl, Alkenyl or Alkyl Halides and Triflates. Eur. J. Org. Chem. 2008, 2013-2030.

(54) Hall, D. G. Boronic Acids: Preparation, Applications in Organic Synthesis and Medicine; Wiley-VCH Verlag GmbH \& Co. KGaA: Weinheim, 2006.

(55) Jana, R.; Pathak, T. P.; Sigman, M. S. Advances in Transition Metal (Pd,Ni,Fe)Catalyzed Cross-Coupling Reactions Using Alkyl-organometallics as Reaction Partners. Chem. Rev. 2011, 111, 1417-1492.

(56) Miyaura, N.; Suzuki, A. Palladium-Catalyzed Cross-Coupling Reactions of Organoboron Compounds. Chem. Rev. 1995, 95, 2457-2483.

(57) Brown, J. Modern Rhodium-Catalysed Organic Reactions. In Modern RhodiumCatalysed Organic Reactions; Evans, P., Ed.; Wiley-VCH: Weinheim, 2005, p 33-54.

(58) Coyne, A. G.; Guiry, P. J. The Development and Application of Rhodium-Catalyzed Hydroboration of Alkenes. In Modern Reduction Methods; Andersson, P. G., Munslow, I. J., Eds.; Wiley-VCH: Weinheim, 2008, p 65-84.

(59) Wu, J. Y.; Moreau, B.; Ritter, T. Iron-Catalyzed 1,4-Hydroboration of 1,3-Dienes. J. Am. Chem. Soc. 2009, 131, 12915-12917.

(60) Zhang, L.; Peng, D.; Leng, X.; Huang, Z. Iron-Catalyzed, Atom-Economical, Chemoand Regioselective Alkene Hydroboration with Pinacolborane. Angew. Chem. Int. Ed. 2013, 52, 3676-3680.

(61) Ogawa, T.; Ruddy, A. J.; Sydora, O. L.; Stradiotto, M.; Turculet, L. Cobalt-and IronCatalyzed Isomerization-Hydroboration of Branched Alkenes: Terminal Hydroboration with Pinacolborane and 1, 3, 2-Diazaborolanes. Organometallics 2016, 36, 417-423.

(62) Nakajima, K.; Kato, T.; Nishibayashi, Y. Hydroboration of Alkynes Catalyzed by Pyrrolide-Based PNP Pincer-Iron Complexes. Org. Lett. 2017, 19, 4323-4326.

(63) Gorgas, N.; Alves, L. G.; Stöger, B.; Martins, A. M.; Veiros, L. F.; Kirchner, K. Stable, Yet Highly Reactive Nonclassical Iron(II) Polyhydride Pincer Complexes: Z-Selective Dimerization and Hydroboration of Terminal Alkynes. J. Am. Chem. Soc. 2017, 139, 8130-8133.

(64) Gorgas, N.; Stöger, B.; Veiros, L. F.; Kirchner, K. Iron (II) Bis (acetylide) Complexes as Key Intermediates in the Catalytic Hydrofunctionalization of Terminal Alkynes. ACS Catal. 2018, 8, 7973-7982. 
(65) Geier, S. J.; Westcott, S. A. Dehydrogenative Borylation: the Dark Horse in MetalCatalyzed Hydroborations and Diborations? Rev. Inorg. Chem. 2015, 35, 69-79.

(66) Wang, C.; Wu, C.; Ge, S. Iron-Catalyzed E-Selective Dehydrogenative Borylation of Vinylarenes with Pinacolborane. ACS Catal. 2016, 6, 7585-7589.

(67) Jiang, S.; Quintero-Duque, S.; Roisnel, T.; Dorcet, V.; Grellier, M.; Sabo-Etienne, S.; Darcel, C.; Sortais, J.-B. Direct Synthesis of Dicarbonyl PCP-Iron Hydride Complexes and Catalytic Dehydrogenative Borylation of Styrene. Dalton Trans. 2016, 45, 1110111108.

(68) Greenhalgh, M. D.; Thomas, S. P. Chemo-, Regio-, and Stereoselective Iron-Catalysed Hydroboration of Alkenes and Alkynes. Chem. Commun. 2013, 49, 11230-11232.

(69) Silverman, G. S.; Rakita, P. E.; Dekker, M. Handbook of Grignard Reagents: New York, 1996.

(70) Ziegler, D. S.; Wei, B.; Knochel, P. Improving the Halogen - Magnesium Exchange by using New Turbo - Grignard Reagents. Chem. Eur. J. 2019, 25, 2695-2703.

(71) Sato, F. The Preparation of Grignard Reagents via the Hydromagnesation Reaction and Their Uses in Organic Synthesis. J. Organomet. Chem. 1985, 285, 53-64.

(72) Greenhalgh, M. D.; Thomas, S. P. Iron-Catalyzed Hydromagnesiation of Olefins. Synlett 2013, 24, 531-534.

(73) Finkbeiner, H. L.; Cooper, G. D. Synthetic Applications of the Titanium-Catalyzed Exchange of Olefins with Grignard Reagents. J. Org. Chem. 1962, 27, 3395-3400.

(74) Tamura, M.; Kochi, J. Iron Catalysis in the Reaction of Grignard Reagents with Alkyl Halides. J. Organomet. Chem. 1971, 31, 289-309.

(75) Tamura, M.; Kochi, J. K. The Reaction of Grignard Reagents with Transition Metal Halides: Coupling, Disproportionation, and exchange with Olefins. Bull. Chem. Soc. Jpn. 1971, 44, 3063-3073.

(76) Shirakawa, E.; Ikeda, D.; Masui, S.; Yoshida, M.; Hayashi, T. Iron-Copper Cooperative Catalysis in the Reactions of Alkyl Grignard Reagents: Exchange Reaction with Alkenes and Carbometalation of Alkynes. J. Am. Chem. Soc. 2012, 134, 272-279.

(77) Shirakawa, E.; Yamagami, T.; Kimura, T.; Yamaguchi, S.; Hayashi, T. Arylmagnesiation of Alkynes Catalyzed Cooperatively by Iron and Copper Complexes. J. Am. Chem. Soc. 2005, 127, 17164-17165. 
Abstract graphic

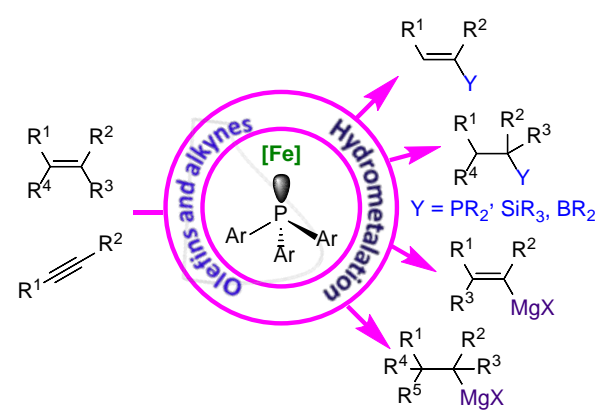

